\title{
Autoimmune Lymphoproliferative Syndrome - Impaired Regulation of the Immune Response by Impaired Induction of Apoptosis
}

\author{
Robert Brawura-Biskupski-Samaha Tomasz Grzela \\ Molecular Cell Biology Laboratory, Department of Histology and Embryology, Biostructure Research Center, Warsaw Medical University, \\ Poland
}

\section{Key Words}

ALPS - Apoptosis - Autoimmune lymphoproliferative syndrome $\cdot$ Caspase $\cdot$ CD95

\begin{abstract}
Summary
Autoimmune lymphoproliferative syndrome (ALPS) is an inherited disease hindering apoptosis of lymphocytes. It includes mutations in genes coding for various components of the apoptotic pathway: CD95 (ALPS 0 and ALPS la), CD178 (ALPS Ib) and caspase-10 (ALPS II). Moreover, patients with genetically inherited caspase-8 or other components of apoptosis-inducing pathway deficiencies (ALPS III) have been described recently. In addition, ALPS-like clinical patterns, including Dianzani's autoimmune lymphoproliferative disease (DALD), were characterized. In this review, we summarize currently known types of ALPS and characterize their immunological and molecular background.
\end{abstract}

\section{Introduction}

In 1967, Virginia C. Canale and Carl H. Smith described 5 cases of children between 3 and 14 years of age that were, during a period of 13 years, admitted at The New York Hospital due to lymphoma-like symptoms [1]. The newly defined disease, called the Canale-Smith syndrome or autoimmune lymphoproliferative syndrome (ALPS) [2-4], was characterized by onset of symptoms between 1 month and 2 years of age, including lymphadenopathy, varying degrees of autoimmune hemolytic anemia, neutropenia and thrombocytopenia $[1,5]$, as

\section{Schlüsselwörter}

ALPS - Apoptose - Autoimmunes lymphoproliferatives Syndrom · Caspase $\cdot$ CD95

\section{Zusammenfassung}

Das autoimmune lymphoproliferative Syndrom (ALPS) ist eine vererbte Störung des Apoptoseprozesses in Lymphozyten. Es umfasst Mutationen in Genen, die der Expression verschiedener Komponenten des Apoptoseprozesses zugrunde liegen: CD95 (ALPS 0 and ALPS la), CD178 (ALPS Ib) und Caspase 10 (ALPS II). Kürzlich wurden zudem Patienten mit ALPS III beschrieben. Unter dem Begriff ALPS III werden derzeit genetisch bedingte Defekte von Caspase 8 oder anderen Komponenten des Apoptose induzierenden Signaltransduktionsweges zusammengefasst. Darüber hinaus sind ALPS-ähnliche klinische Bilder bekannt, wie die Dianzani-Erkrankung (Dianzani's autoimmune lymphoproliferative disease; DALD). Die vorliegende Übersichtsarbeit fasst die derzeit bekannten ALPS zusammen und beschreibt ihren immunologischen und molekularen Hintergrund.

well as an increase of peripheral T cell receptor $\alpha \beta$ (TCR $\alpha \beta)$ CD4- CD8- double negative (DN) T cells [6-8]. Further research was enabled by the discovery of 2 mice MRL strand mutants, $l p r$ and $g l d$, displaying an autoimmune lymphoproliferative phenotype [9]. However, despite extensive studies, the genetic background of the syndrome described by Canale and Smith remained unidentified until the early 1990s. Finally, the molecular characteristic of ALPS was established after the discovery and cloning of CD95 (also known as Fas/APO1/TNFRSF6) [10-12] and its ligand CD178 (FasL/APO-1L) [13-14].

\begin{tabular}{ll}
\hline KARGER & ( 2006 S. Karger GmbH, Freiburg \\
Fax +497614520714 & Accessible online at: \\
$\begin{array}{l}\text { E-mail Information@Karger.de } \\
\text { www.karger.com }\end{array}$ & www.karger.com/tmh \\
&
\end{tabular}

Tomasz Grzela, M.D., PhD

Molecular Cell Biology Laboratory, Department of Histology and Embryology

Biostructure Research Center, Warsaw Medical University

5 Chalubinskiego Str, 02004 Warsaw, Poland

Tel./Fax +48226295282

E-mail tgrzela@ib.amwaw.edu.pl 


\section{Death Receptors and Induction of Apoptosis}

The CD178 (CD95L/FasL/APO-1L) molecule is a physiological ligand for CD95. It belongs to the ever expanding tumor necrosis factor (TNF) family which also includes TNF, lymphotoxin (LT)- $\alpha / \beta$, TRAIL/APO-2L, TRANCE/RANKL, LIGHT, TWEAK/APO-3L, APRIL, BAFF/TALL-1, CD70/ CD27L, CD153/CD30L, CD154/CD40L, AITRL/GITRL, CD 134L/OX40L and ectodysplasin A (EDA) [15-17].

Similarly to other members of the TNF family, CD178 is synthesized as a type 2 transmembrane protein that could be cleaved by matrix metalloproteinase (MMP)-7 to form a less active soluble molecule [18]. The tightly controlled expression of CD178 is restricted to activated T cells and natural killer (NK) cells, thus indicating the key role it plays in the mechanisms of cytotoxicity [19, 20]. Recently, it has been postulated that, in addition to the precise transcriptional regulation and MMP-7-dependent posttranslational modification, the activity of CD178 could also be controlled by an alternative premRNA splicing [21, 22]. On the other hand, the constitutive expression of CD178 was found in the testis and the eye, where it is supposed to maintain the immunoprivilege site status [23, 24].

The CD95 molecule, also known as Fas, APO-1 or, most recently, TNFRSF6, is a plasma membrane-anchored type- 1 glycoprotein which is a typical representative of the TNF receptor (TNFR) superfamily [16, 25-27]. The members of this family are characterized by extracellular fragments containing up to 6 cysteine-rich domains (CRDs). The TNFR superfamily is divided into 2 groups. The first group comprises glycoproteins with an intracellular functional domain known as 'death domain' (DD). DD is responsible for apoptosis-inducing signal transmission, and thus determines the biological activity of the receptor molecule $[25,26]$. The remaining molecules are lacking of DD and, therefore, they activate other signaling pathways $[26,28]$.

CD95 consists of 3 extracellular CRDs, a transmembrane anchoring segment and an intracellular DD formed of 80 amino acid residues [29]. The expression of CD95 is ubiquitous but particularly abundant in T lymphocytes and activated B lymphocytes, thus underlying the significance of this molecule in the immune homeostasis $[20,30]$. The binding of CD178 to the CD95 receptor molecule is supposed to induce homotrimer formation and trigger the apoptosis signaling pathway [27]. Recently, some authors postulated the occurrence of previous receptor trimerization through the pre-ligand association domain (PLAD) [31, 32]. According to that hypothesis, CD178 binding would result in the formation of multiple CD95 trimeric clusters with the engagement of 6 or more receptor molecules that enabling the multiplication of the apoptosis-inducing signal.

CD95 DD cluster formation induces conformational changes leading to the attachment of the Fas-associated DD (FADD) adapter protein [33]. The FADD molecule is composed of its own DD and another domain, known as the death effector domain (DED). Binding of the adapter molecule occurs through homophilic DD interaction between the DD of the CD95 receptor and that of the FADD, resulting in the formation of the death-inducing signaling complex (DISC) [27, 30]. The DED component of the FADD adapter protein is responsible for further binding of the pro-enzyme pro-caspase-8, (formerly known as FADD-like IL-1-converting enzyme; FLICE) and/or pro-caspase-10 (FLICE2) [34-37]. Both belong to the family of caspases (cysteinyl-aspartate-specific proteases) which are synthesized as inactive pro-enzymes. Both are composed of a caspase-recruiting domain (CARD) and large p20 and small p10 protease subunits. The activated caspases can further activate downstream effector pro-caspases, such as caspase-3, -6 and -7 , which are responsible for the cleavage of cellular substrates and finally lead to cell death [30, 38]. In addition, active caspase- 8 may also cleave the cytosolic Bid protein which induces mitochondrial outer membrane permeabilization (MOMP) and release of serine proteinase HtrA2/Omi and cytochrome $\mathrm{C}$ from the mitochondria [39-41]. The cytochrome $\mathrm{C}$ attaches to apoptotic protease-activating factor-1 (APAF-1) and activates pro-caspase-9 [42, 43].

Recent studies have shown that, similarly to other death receptors, the CD95 signaling pathway is much more complex than originally assumed [30]. The number of proteins that interact with and modulate DISC activity is still increasing and includes: death-associated protein (DAXX) [44], receptor-interacting protein kinase (RIP)-1 [45], RIP-associated protein with DD (RAIDD) [28], FLICE-inhibitory protein (FLIP) [46], FADD-interacting serine/threonine kinase (FIST/ HIPK3) [47], Fas-associated factor (FAF)-1 [48], Fas-associated protein phosphatase (FAP)-1 [49], FLICE-associated huge protein (FLASH) [50], the Src kinase family members Lck and Fyn [51], the ubiquitin-like protein sentrin and its ligase ubiquitin-conjugating enzyme Fas-associated protein (UBCFAP) $[52,53]$ and many others. Therefore, in addition to the caspase cascade, CD95 triggering involves several caspase-independent signals, such as the activation of sphingomyelinases and generation of ceramides, activation of p38 mitogen-activated protein kinase (MAPK), extracellular signal-regulated kinase (ERK), as well as c-Jun N-terminal kinase (JNK) and nuclear factor (NF)- $\mathrm{BB}$ pathways (fig. 1) [15, 30, 54]. Unexpectedly, a broad activation of the cellular metabolism by the CD95 death receptor might result, in certain circumstances, not only in apoptosis inhibition and cell survival but in cell proliferation [30, 43]. On the other hand, however, such a pleiotropic mechanism enables the effective substitution of defective or lacking single component or even entire signaling pathway. This could explain, at least in part, the usually weak biological consequences of impaired apoptosis induction caused by a single mutation [27, 30, 43].

It is noteworthy that, in addition to the previously mentioned inhibitor FLIP, the activity of caspases is also controlled by 2 big families of apoptosis modulators - the Bcl/Bax superfami- 


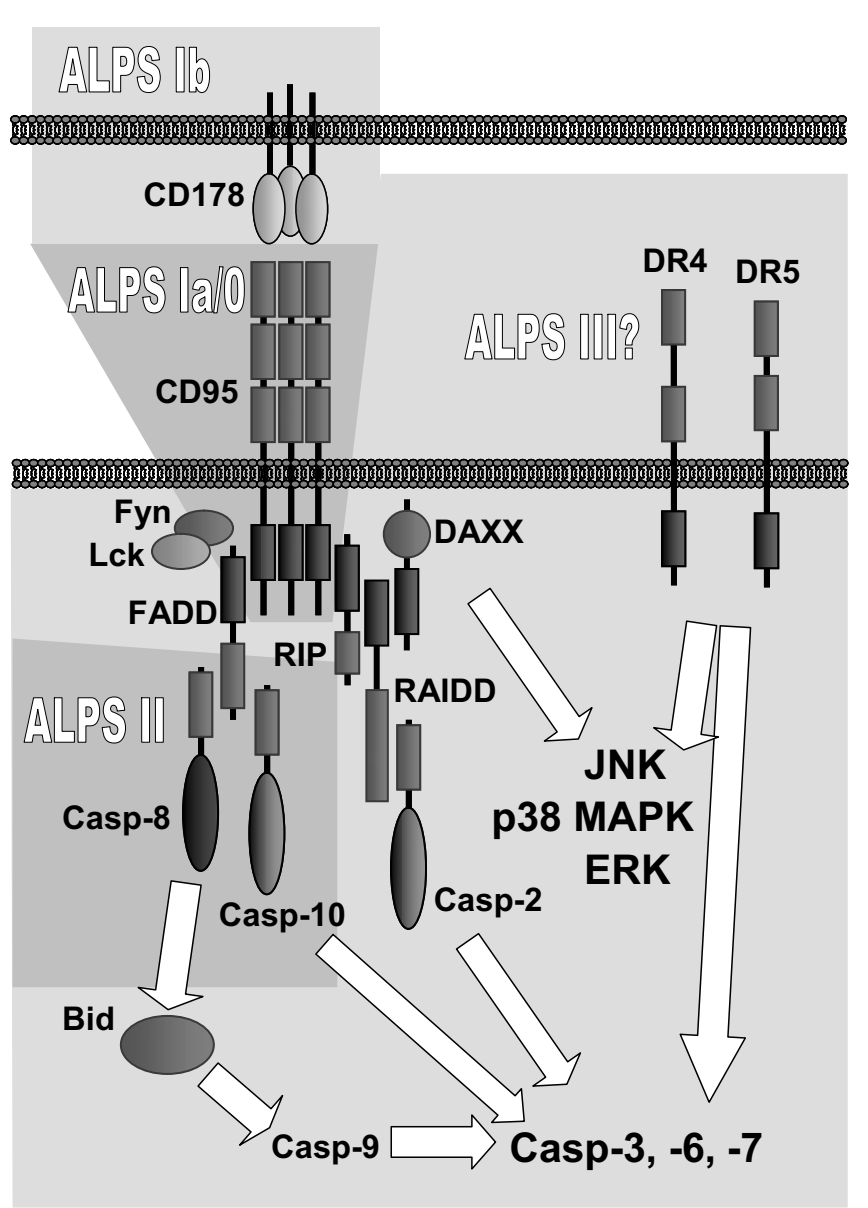

Fig. 1. The CD178-CD95 signaling pathway. Grey areas correspond to constituents of the pathway, presumably affected in the respective ALPS types.

ly and inhibitors of apoptosis (IAPs) [30, 43]. It has been well documented that some of them could play a key role in the regulation of apoptosis during immune response [30, 43, 55]. Pronounced upregulation of Bcl-2 and FLIP has been proven to occur in the initial phase of lymphocytes activation [55]. This could explain the marked resistance of activated lymphocytes to apoptosis induction via CD95, although the latter is upregulated, too. Within a few days, at high levels of IL-2, both apoptosis inhibitors are downregulated, resulting in resensitization of the lymphocytes to CD178, followed by extensive elimination of activated cells [56-58].

\section{Immunological Aspects of Autoimmune Lympho- proliferative Syndrome}

The interaction between the CD178 and CD95 molecules results in extensive apoptosis of activated lymphocytes (AICD, activation-induced cell death) and is currently considered an important regulatory mechanism of lymphocyte action [20, 59, 60]. According to this concept, the apoptosis-mediated silenc- ing of immune response is crucial for controlling the peripheral lymphocyte pool size. Otherwise, it would expand as a result of further responses during life. Therefore, due to disturbances in the CD178-CD95 pathway, impaired apoptosis induction in lymphocytes will result in their accumulation and the enlargement of peripheral lymphatic organs (lymph nodes and spleen), thus leading to the development of typical symptoms of ALPS - lymphadenopathy and splenomegaly [4, 7, 8]. As previously suggested, enlargement of lymphatic organs is due to both increased proliferation and impaired AICD. Immunostaining of ALPS patient-derived lymph nodes showed normal $\mathrm{T}$ cell phenotypes (predominantly $\mathrm{CD} 4+$ ) and an apoptosis frequency comparable to healthy controls in the germinal centers, but an increase of DN T cells in the paracortical T-zone. They displayed positive staining for the proliferation marker Ki-67, numerous mitotic figures and significantly decreased apoptosis, detected by TUNEL analysis (in situ detection of fragmented DNA) [61].

The most significant immunological abnormality found in ALPS patients is the pronounced increase in circulating TCR $\alpha \beta$ CD3+ CD4- CD8- DN T lymphocytes [62]. In healthy individuals, this population constitutes less than $1-2 \%$ of lymphocytes in the peripheral blood $[62,63]$, thymus and skin [61]. The role and origin of this population remain unclear. Interestingly, it has been shown that DN T cells express $\mathrm{T}$ cell intracellular antigen(TIA)-1 and perforin, markers of CD8+ cytotoxic T lymphocytes [61]. Moreover, DN T cells found in ALPS patients express HLA-DR which is considered a previous activation marker [62]. However, Sneller et al. [6] and Fuss et al. [64] have shown that DN T cells derived from ALPS patients poorly respond to mitogen or antigen and do not express cytokines after in vitro stimulation, thus displaying anergic behavior. On the other hand, some authors have proposed that DN T lymphocytes could play a regulatory role for syngeneic CD4+ CD8+ T cells in immune responses against alloantigens [65] or even kill allogeneic tumor target cells [66]. Taken together, these findings support the thesis that DN T cells originate from chronically activated CD8+ populations [61]. However, this subject requires further studies. Recently, a human model for studying DN T cells has been described, where the CD8 mutation resulting in a significantly increased DN T cell count and mild immunodeficiency might facilitate better comprehension of the biology of this population [67]. Also, it is noteworthy that, in addition to TCR $\alpha \beta$ DN T cells, an expansion of TCR $\gamma \delta$ DN T cells and CD8+CD57+ T cells, as well as a decrease in CD4+ CD25+ regulatory $\mathrm{T}$ cells have been observed in ALPS patients [68, 69]. Nevertheless, the immunological and clinical significance of these populations remains yet to be clarified.

The silencing of immune reactions presumably decreases the risk of autoimmunity. Indeed, it has been proven that an uncontrolled immune response that continues after elimination of the invading pathogen would result in cross-reactive recognition of self-antigens by activated lymphocytes [70, 71]. 
Therefore, similarly to $\mathrm{T}$ lymphocytes, also function and homeostasis of B lymphocytes is under the control of the CD178-CD95 system [72]. In addition, impaired regulation of immune responses in ALPS is associated with predominance of the Th2 subpopulation. Consequently, ALPS patients display a Th2-characteristic cytokine profile, including decreased secretion of IL-2 and IFN- $\gamma$, whereas IL-4, IL-5 and IL-10 levels are significantly elevated compared to healthy subjects [64]. These conditions promote polyclonal B cell activation and expansion with a significant increase in the CD5+ B cell subpopulation, and hypergammaglobulinemia with autoreactive antibodies, predisposing to development of autoimmune manifestations [69]. In fact, as reported by several groups, such antibodies, especially IgG and IgA directed against erythrocytes, platelets, anti-cardiolipin and anti-nuclear antibodies, anti-dsDNA and anti-U1-RNP were found in ALPS patients $[7,73]$. Thus, the most frequent ALPS-associated autoimmune symptoms include autoimmune hemolytic anemia, thrombocytopenia and neutropenia, glomerulonephritis, polyneuropathy, urticaria and vasculitis [63]. Interestingly, ALPS symptoms usually occur at the age of 1 month to 2 years. However, a few cases of patients with onset of symptoms at more advanced age, with the oldest reported patient being age 54 , have also been reported [73, 74].

In addition, since the CD178-CD95 system plays an important role in anti-cancer defense, its impaired function could bias towards hematological or solid cancer development. Indeed, in some ALPS patients, Hodgkin's or non-Hodgkin's lymphomas, liver carcinoma (with hepatitis $\mathrm{C}$ infection), multiple thyroid or breast adenomas and basal cell carcinomas were observed $[61,75,76]$. This predisposition is particularly visible in individuals with combined defects, e.g. impaired CD95-dependent pathway accompanied by mutation of genes encoding granzymes or perforin [76, 77].

\section{Murine Models of Autoimmune Lymphoproliferative Syndrome}

The mouse model of ALPS was first described in the MRL strain by Andrews et al. [78] and was further characterized as an autosomal recessive $\operatorname{lpr}$ (lymphoproliferation) mutation that was mapped to the mouse chromosome 19 [79]. Subsequently, Roths et al. [80] identified another mutant very similar to $l p r$ which was designated as gld (generalized lymphoproliferative disorder) and, as an autosomal recessive mutation, was localized on the mouse chromosome 1 [81]. Furthermore, the allelic lpr mutation in the CBA/K1Jms mouse strain coexisting with heterozygous gld mutation and, therefore, designated as $l p r^{c g}(l p r$ complementing gld), has been described [82].

The MRL/lpr as well as gld mutants displayed lymphadenopathy and splenomegaly, with accumulation of the unusual subsets of T cells and autoantibody-producing B cells, with large

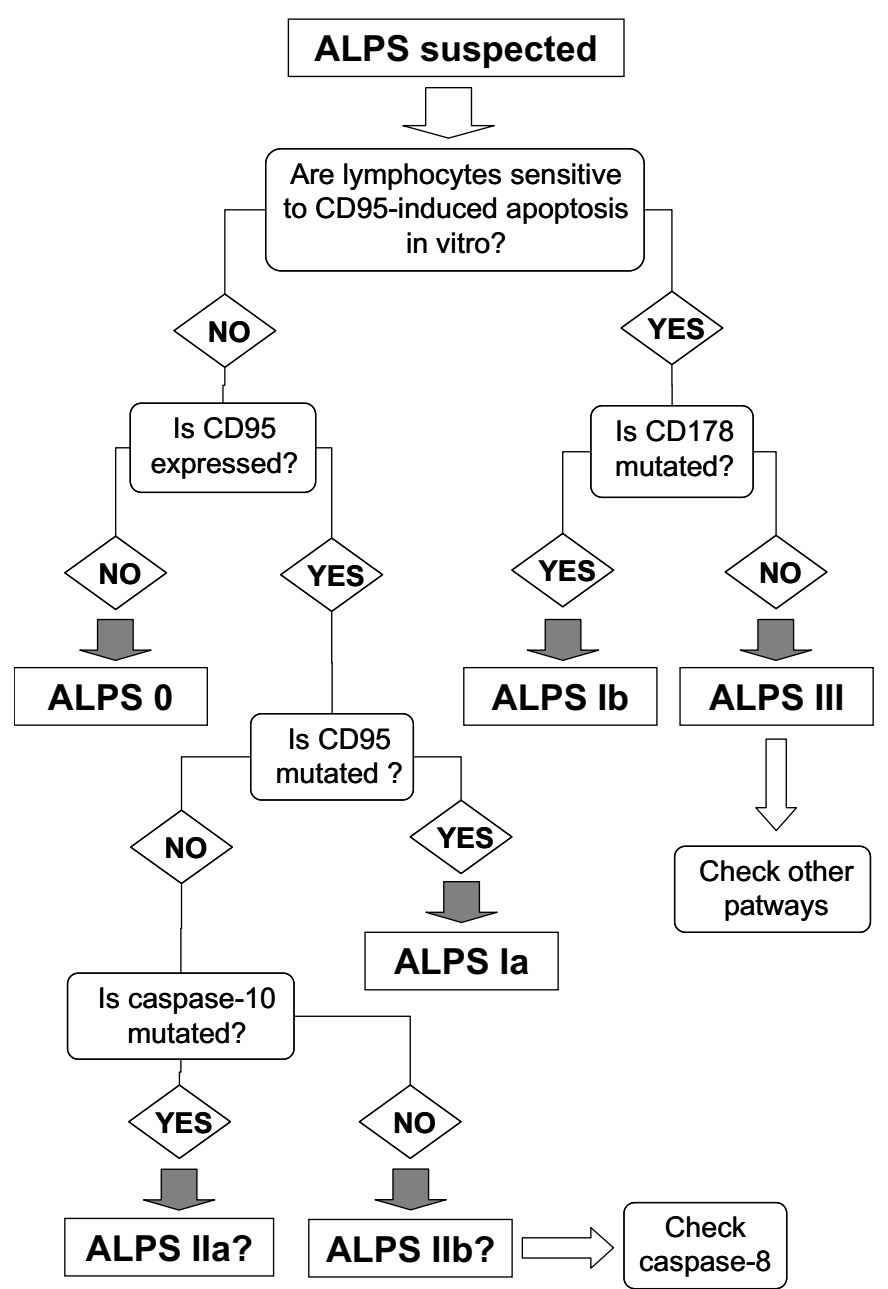

Fig. 2. The proposed algorithm of the ALPS classification.

amounts of $\mathrm{IgG}$ and $\operatorname{IgM}$ autoantibodies, including anti-DNA and rheumatoid factor antibodies. The development of autoimmune diseases, predominantly arthritis and nephritis, causes the mice to die at approximately 5 months of age. The phenotype of the lymphocytes that accumulate in the lymph nodes and spleen is similar to that observed in ALPS patients, including CD4- CD8- DN T cells [9, 83].

The further genetic studies on $l p r$ and $g l d$ mice identified the genes affected by these mutations, thus confirming the close molecular similarity to human ALPS. In lpr mice, a splicing defect and thus premature termination and extremely reduced expression of the CD95 receptor is caused by the insertion of a retroviral early transposable element (ETn) into intron 2 of the FAS gene [84, 85]. The ETn carries poly(A) adenylation signals (AATAAA) on the long terminal repeat (LTR) sequences, and thus it is believed that the FAS transcript that starts from exon 1 terminates prematurely in intron 2 and is sliced $[9,86]$.

In contrast to the $l p r$ mutants, $l p r^{c g}$ mice express the full length FAS mRNA and CD95 receptor molecule. However, in $l p r^{c g}$ 
mice, due to a point mutation ( $\mathrm{T}$ to $\mathrm{A}$ ) in the intracellular DD resulting in an amino acid change (from isoleucine to asparagine), the apoptotic signal through CD95 is not transmitted $[9,12]$.

The gld mutation consisting of a point mutation ( $\mathrm{T}$ to $\mathrm{C}$ ), affects the C-end of the CD178 molecule. This results in the replacement of phenylalanine with leucine, thus disabling the CD178-CD95 interaction [14, 85].

\section{Types and Characteristics of Human Autoimmune Lymphoproliferative Syndrome}

As mentioned before, ALPS patients display a characteristic phenotype that includes lymphadenopathy and splenomegaly, increase in TCR $\alpha \beta$ CD4- CD8- DN T cells and autoimmune symptoms. Thus, they assemble the basic clinical criteria, which, associated with mutation analysis, are required to identify ALPS. In spite of a few exceptions, ALPS patients have at least 3 of the listed symptoms. Moreover, in humans, diagnosis of ALPS can be confirmed by functional analysis of patient lymphocyte sensitivity to anti-CD95 antibody-induced apoptosis in vitro [27]. The proposed algorithm of the ALPS classification is shown in figure 2.

According to particular genotypic characteristics, ALPS patients are classified as follows: ALPS 0 (homozygous FAS/ CD95 mutation) [8, 87], ALPS Ia (heterozygous FAS/CD95 mutation) [27], ALPS Ib (FASLG/CD178 mutation) [88], ALPS II (caspase-10 mutation) [89] and ALPS III (target unknown) [27] (fig. 1).

\section{ALPSO}

The first case of ALPS 0 was characterized by Rieux-Laucat et al. [8] in a patient born to consanguineous parents. The infant displayed massive lymphoproliferation suggesting a prenatal onset. A further 2 cases were very similar, with prenatal onset of extreme lymphoproliferation and lung infiltration, leading to the early death of 1 patient [87, 90]. Lymphoproliferation involved both $\mathrm{T}$ and $\mathrm{B}$ lymphocytes, with peripheral blood lymphocytes comprising more than $70 \%$ of DN T cells. A great number of mitotic figures in the spleen and lymph node sections suggested active lymphocyte proliferation rather than a simple accumulation. The patient's lymphocytes were not responding to anti-CD95 antibody-induced apoptosis in vitro. On the other hand, some apoptotic lymphocytes were observed on the blood smears, thus suggesting activation of alternative death pathways [27].

Molecular analysis has shown that ALPS 0 is caused by complete CD95 molecule deficiency as a result of a homozygous null mutation. In 2 cases, the mutation affected exon 9 which encodes the DD of the CD95 receptor. These mutants, although non-functional, should be present on the cell surface.
However, presumably, the defective protein might be unstable and prematurely eliminated, or, as a novel-peptide, is accumulated in the endoplasmic reticulum [91]. Another stop-coding mutation that affects the extracellular domain of the receptor, results in premature termination and generation of short CD95 forms which do not anchor in the plasma membrane [63].

\section{ALPS Ia}

In contrast to homozygous ALPS 0 patients, only around 70\% of heterozygous carriers of CD95 mutations exhibit clinical symptoms. The amplitude of the defect differs between each ALPS Ia patient. Symptoms usually commence between 0 and 5 years of age, with most cases involving a range of 6-12 months [7, 63]. Lymphoproliferation is the most prominent symptom leading to hepato-splenomegaly and lymphadenopathy. Lymphoproliferation and subsequent accumulation of $\mathrm{T}$ and B lymphocytes in the paracortical areas of lymphoid organs results in their enlargement without altering the overall structure. In all cases, a DN T cell subpopulation was found. However, its percentage varies between 2 and 61\% [63].

Autoimmune symptoms are the second most frequent clinical manifestation of ALPS. As previously described, they include autoimmune hemolytic anemia, thrombocytopenia, neutropenia, urticaria, vasculitis as well as glomerulonephritis and Guillain-Barré syndrome [63]. Furthermore, recently, Bona et al. [92] proved that mutations affecting CD95 might lead to other autoimmune diseases. They found that the impaired function of CD95 might be associated with an increased frequency of autoimmune thyroid diseases, including Grave's disease (GD) and Hashimoto's thyroiditis (HT) in pediatric patients.

ALPS Ia is characterized by heterozygous mutations of the FAS/CD95 gene. The majority of so far reported FAS mutations (approximately two thirds) affect exon 9 which encodes the DD. At least 1 patient has been described with an exon 8 -located mutation [93]. The deletion of exon 8 which contains 25 nucleotides leads to a frameshift and premature termination after 3 missense codons. Recently, Goldman et al. [5] described 2 patients with novel mutations. The first patient displayed a base pair substitution in the $5^{\prime}$ splice sequence of intron 8 , which resulted in deletion of exon 8 . The second patient exhibited a new complex deletion resulting in a frameshift and missense substitution within exon 9. Clinical symptoms appear in approximately 75 and $90 \%$ of patients with truncated and missense-mutated intracellular portion of CD95, respectively. DNA changes were also found by Bona et al. [92] in exons 2, 3 and 7. All of these mutations corresponded to silent DNA changes or common polymorphisms.

Approximately $30 \%$ of $F A S / C D 95$ mutations deal with the extracellular domain. Usually, they are accompanied by a less significant impairment of CD95-mediated apoptosis induction 
and clinical penetrance of approximately $30 \%$. These mutations reveal a defective CD95 molecule which is either incapable of anchoring in the plasma membrane, or, more likely, unable to interact with CD178 [27].

\section{ALPS Ib}

ALPS Ib was ascribed to a patient with systemic lupus erythematosus accompanied with lymphoproliferation. Interestingly, the clinical manifestations did not include DN T cells and splenomegaly. Therefore, due to the absence of basic symptoms of 'normal' ALPS, the case was classified as ALPS Ib. The genetic studies revealed a dominant FASLG/CD178 mutation, similar to that of gld mice [88].

\section{ALPS II}

A number of patients have been described with clinical symptoms of ALPS, including impaired CD95-mediated lymphocytes apoptosis, but without mutation of the FAS/CD95 gene [7, 89]. Intriguingly, triggering of other death receptors, including TNF-RI/TNFRSF1A/CD120a, DR3/TNFRSF12/ APO-3, DR4/TNFRSF10A/TRAIL-R1/APO-2 and DR5/TNFRSF10B/TRAIL-R2/KILLER, in these patients, also revealed impaired induction of apoptosis [63]. This could suggest a defective shared element in the apoptotic pathways induced by each of the receptors mentioned above. Indeed, it has been proven that these patients displayed mutations affecting the initiator caspase-10 [36, 37, 89].

Amazingly, in addition to the accumulation of T and B lymphocytes, patients with mutated caspase-10 demonstrated the accumulation of dendritic cells, a unique feature not observed in any other ALPS type. Moreover, they exhibited exceedingly acute autoimmune hemolytic anemia, thrombocytopenia, optic neuritis and meningitis [63].

Recently, Chun et al. [94] described 2 siblings, a 12-year-old female and an 11-year-old male, with defective lymphocyte homeostasis and apoptosis and impaired activation of $\mathrm{T}$ and $\mathrm{B}$ lymphocytes and NK cells. Molecular analysis revealed caspase- 8 mutations. Interestingly, further studies showed that mutated caspase-10 and caspase- 8 may cross-inhibit, although DISC recruitment is not impaired [36]. Also, 1 case of a 5-yearold female with an ALPS-like phenotype, impaired CD95-mediated induction of apoptosis and decreased expression of caspase- 8 has been reported by our group. However, due to the absence of DN T cells, the described patient presumably should not be classified as a typical ALPS patient [95]

Due to the fact that caspase- 10 and -8 mutations alter 2 different elements on the same level of the apoptotic pathway, it is plausible that 2 distinct subtypes of ALPS II should be considered, rendering e.g. ALPS IIa for caspase-10 and ALPS IIb for caspase-8 (fig. 2).
It is noteworthy that one of the difficulties with ALPS II is the lack of a respective mouse model, since caspase-10 which takes part in the apoptotic pathway in humans, does not exist in mice. Thus, homozygous caspase- 8 deficiency in mice leads to embryonic lethality clearly demonstrating its importance in development [96].

\section{ALPS III}

Over 30 patients with a mild form of typical ALPS symptoms have been investigated by the group of Rieux-Laucat [63]. The patients displayed hypergammaglobulinemia and an increase in DN T cells in the peripheral blood. Surprisingly, they did not reveal any defects of the CD178-CD95 pathway, with no molecular abnormality established so far [63]. It has been proposed that another apoptotic pathway could be afflicted. This thesis might be supported by animal studies with knockout mice lacking other death receptors, such as DR3 or DR6. DR3-deficient mice displayed impaired apoptosis during negative selection in the thymus, resulting in the generation of autoreactive T cells, whereas DR6-lacking animals revealed an increased proliferation of CD4+ T cells with significant Th2 polarization [97, 98]. Nevertheless, the significance of both receptors in CD95-independent homeostasis of the immune system and development of ALPS symptoms requires further investigation. Moreover, the involvement of other components of death receptor-activated pathways, including JNK, MAPK or some of the apoptosis regulators, cannot be excluded [63].

\section{Dianzani's Autoimmune Lymphoproliferative Disease}

Aside from the 5 ALPS types, Dianzani et al. [74] have reported several patients with symptoms similar to that of ALPS. These unrelated patients exhibited decreased function of CD95, without any detectable FAS/CD95 or FASLG/ CD178 mutations. Most of the patients' parents were CD95resistant, which would imply an inherited trait. The T cells of the majority of the patients were also resistant to apoptosis induced by ceramides, thus suggesting the possibility of mutations affecting the CD95 pathway downstream from the death receptor. In contrast to ALPS patients, these individuals lack DN T cells.

Since this disease is similar to ALPS but does not exhibit the complete pattern of ALPS, it has been named autoimmune lymphoproliferative disease (ALD). To avoid confusion with another ALD acronym (for adrenoleukodystrophy), the name Dianzani's ALD (DALD) has been proposed in the OMIM NCBI site (www.ncbi.nlm.nih.gov/entrez/query.fcgi?db = OMIM) to describe this disease which lacks any recognized CD178-CD95 mutations and DN T cell expansion [74].

DALD seems to be genetically heterogeneous, with the final outcome of the disease differing among families, thus demon- 
strating different genetic backgrounds. As a result, several gene alterations may be needed to cause the disease. Given the observations of Dianzani et al. [99], it was suggested by the authors that different subjects carry different mutations, and the accumulation of these mutations may lead to the disease. This was deduced from the fact that in most cases both parents displayed defective CD95 function but did not manifest the disease. In many cases, the patients displayed resistance to both anti-CD95 antibody-induced and ceramide-induced cell death, whereas many of their parents presented resistance to only one of them. Moreover, the DALD families also revealed an increased frequency of cancers with no particular type dominating.

\section{Conclusions}

The impaired induction of apoptosis observed in ALPS patients, results from mutations altering the CD178-CD95 system. Recently, in addition to CD178 and CD95, the role of other molecules, including caspase- 10 and -8 as well as other death receptors, has been investigated in the pathogenesis of ALPS. Thus, future studies should focus on further clarification of molecules involved in ALPS II and III, and in particular on the connection between apoptosis and other signaling pathways. It is noteworthy that ALPS could also serve as a very attractive model for the better understanding of several aspects of immune system function, including immune response regulation, induction of autoimmune reactions and development of cancer.

\section{References}

1 Canale VC, Smith CH: Chronic lymphadenopathy simulating malignant lymphoma. J Pediatr 1967;70: 891-899.

2 Drappa J, Vaishnaw AK, Sullivan KE, Chu JL, Elkon KB: Fas gene mutations in the Canale-Smith syndrome, an inherited lymphoproliferative disorder associated with autoimmunity. N Engl J Med 1996;335:1643-1649.

3 Malzberg MS, Haller JO, Snieckus PJ, Halpern SL: Canale-Smith syndrome: chronic pseudomalignant lymphadenopathy. J Clin Ultrasound 1991;19: 172-174.

4 Fisher GH, Rosenberg FJ, Straus SE, Dale JK, Middleton LA, Lin AY, Strober W, Lenardo MJ, Puck JM: Dominant interfering Fas gene mutations impair apoptosis in a human autoimmune lymphoproliferative syndrome. Cell 1995;81:935-946.

$\checkmark 5$ Goldman FD, Vibhakar R, Puck JM, Straus SE, Ballas ZK, Hollenback C, Loew T, Thompson A, Song K, Cook RT: Aberrant T-cell antigen receptor-mediated responses in autoimmune lymphoproliferative syndrome. Clin Immunol 2002;104:31-39.

6 Sneller MC, Straus SE, Jaffe ES, Jaffe JS, Fleisher TA, Stetler-Stevenson M, Strober W: A novel lymphoproliferative/autoimmune syndrome resembling murine lpr/gld disease. J Clin Invest 1992;90: 334-341.

7 Sneller MC, Wang J, Dale JK, Strober W, Middelton LA, Choi Y, Fleisher TA, Lim MS, Jaffe ES, Puck JM, Lenardo MJ, Straus SE: Clincial, immunologic, and genetic features of an autoimmune lymphoproliferative syndrome associated with abnormal lymphocyte apoptosis. Blood 1997;89: 1341-1348.

8 Rieux-Laucat F, Le Deist F, Hivroz C, Roberts IA, Debatin KM, Fischer A, de Villartay JP: Mutations in Fas associated with human lymphoproliferative syndrome and autoimmunity. Science 1995;268: 1347-1349.

9 Nagata S, Suda T: Fas and Fas ligand: lpr and gld mutations. Immunol Today 1995;16:39-43.

10 Yonehara S, Ishii A, Yonehara M: A cell-killing monoclonal antibody (anti-Fas) to a cell surface antigen co-downregulated with the receptor of tumor necrosis factor. J Exp Med 1989;169:17471756.

11 Trauth BC, Klas C, Peters AM, Matzku S, Moller P, Falk W, Debatin KM, Krammer PH: Monoclonal antibody-mediated tumor regression by induction of apoptosis. Science 1989;245:301-305.
12 Watanabe-Fukunaga R, Brannan CI, Itoh N, Yonehara S, Copeland NG, Jenkins NA, Nagata S: Lymphoproliferation disorder in mice explained by defects in Fas antigen that mediates apoptosis. Nature 1992:356:314-317.

13 Rouvier E, Luciani MF, Golstein P: Fas involvement in $\mathrm{Ca}(2+)$-independent $\mathrm{T}$ cell-mediated cytotoxicity. J Exp Med 1993;177:195-200.

14 Takahashi T, Tanaka M, Brannan CI, Jenkins NA, Copeland NG, Suda T, Nagata S: Generalized lymphoproliferation disease in mice, caused by a point mutation in the Fas ligand. Cell 1994;76:969-976.

15 Choi C, Benveniste EN: Fas ligand/Fas system in the brain: regulator of immune and apoptotic responses. Brain Res Brain Res Rev 2004;44:65-81.

16 Locksley RM, Killeen N, Lenardo MJ: The TNF and TNF receptor superfamilies: integrating mammalian biology. Cell 2001;104:487-501.

17 Wisniewski SA, Kobielak A, Trzeciak WH, Kobielak K: Recent advances in understanding of the molecular basis of anhidrotic ectodermal dysplasia: discovery of a ligand, ectodysplasin A and its two receptors. J Appl Genet 2002;43:97-107.

18 Tanaka M, Itai T, Adachi M, Nagata S: Downregulation of Fas ligand by shedding. Nat Med 1998; 4:31-36.

19 Suda T, Takahashi T, Golstein P, Nagata S: Molecular cloning and expression of the Fas ligand, a novel member of the tumor necrosis factor family. Cell 1993;75:1169-1178.

20 Li-Weber M, Krammer PH: Function and regulation of the CD95 (APO-1/Fas) ligand in the immune system. Semin Immunol 2003;15:145-157.

-21 Ayroldi E, D'Adamio F, Zollo O, Agostini M, Moraca R, Cannarile L, Migliorati G, Delfino DV, Riccardi C: Cloning and expression of a short Fas ligand: A new alternatively spliced product of the mouse Fas ligand gene. Blood 1999;94:3456-3467.

22 Schwerk C, Schulze-Osthoff K: Regulation of apoptosis by alternative pre-mRNA splicing. $\mathrm{Mol}$ Cell 2005;19:1-13.

23 Griffith TS, Brunner T, Fletcher SM, Green DR, Ferguson TA: Fas ligand-induced apoptosis as a mechanism of immune privilege. Science 1995;270: 1189-1192.

24 Green DR, Ferguson TA: The role of Fas ligand in immune privilege. Nat Rev Mol Cell Biol 2001;2: 917-924.
25 Smith CA, Farrah T, Goodwin RG: The TNF receptor superfamily of cellular and viral proteins: activation, costimulation, and death. Cell 1994;76: 959-962.

26 Ashkenazi A, Dixit VM: Death receptors: signaling and modulation. Science 1998;281:1305-1308.

27 Rieux-Laucat F, Fischer A, Deist FL: Cell-death signaling and human disease. Curr Opin Immunol 2003;15:325-331.

28 Ashkenazi A, Dixit VM: Apoptosis control by death and decoy receptors. Curr Opin Cell Biol 1999;11:255-260.

29 Oehm A, Behrmann I, Falk W, Pawlita M, Maier G, Klas C, Li-Weber M, Richards S, Dhein J, Trauth BC: Purification and molecular cloning of the APO-1 cell surface antigen, a member of the tumor necrosis factor/nerve growth factor receptor superfamily. Sequence identity with the Fas antigen. J Biol Chem 1992;267:10709-10715.

30 Curtin JF, Cotter TG: Live and let die: regulatory mechanisms in Fas-mediated apoptosis. Cell Signal 2003;15:983-992.

31 Golstein P: Signal transduction. FasL binds preassembled Fas. Science 2000;288:2328-2329.

32 Siegel RM, Frederiksen JK, Zacharias DA, Chan FK, Johnson M, Lynch D, Tsien RY, Lenardo MJ: Fas preassociation required for apoptosis signaling and dominant inhibition by pathogenic mutations. Science 2000;288:2354-2357.

33 Chinnaiyan AM, O'Rourke K, Tewari M, Dixit VM: FADD, a novel death domain-containing protein, interacts with the death domain of Fas and initiates apoptosis. Cell 1995;81:505-512.

34 Muzio M, Chinnaiyan AM, Kischkel FC, O'Rourke K, Shevchenko A, Ni J, Scaffidi C, Bretz JD, Zhang M, Gentz R, Mann M, Krammer PH, Peter ME, Dixit VM: FLICE, a novel FADD-homologous ICE/CED-3-like protease, is recruited to the CD95 (Fas/APO-1) death-inducing signaling complex. Cell 1996;85:817-827.

35 Algeciras-Schimnich A, Shen L, Barnhart BC, Murmann AE, Burkhardt JK, Peter ME: Molecular ordering of the initial signaling events of CD95. Mol Cell Biol 2002;22:207-220.

36 Wang J, Chun HJ, Wong W, Spencer DM, Lenardo MJ: Caspase-10 is an initiator caspase in death receptor signaling. Proc Natl Acad Sci U S A 2001;98: 13884-13888. 
37 Kischkel FC, Lawrence DA, Tinel A, LeBlanc H, Virmani A, Schow P, Gazdar A, Blenis J, Arnott D, Ashkenazi A: Death receptor recruitment of endogenous caspase-10 and apoptosis initiation in the absence of caspase-8. J Biol Chem 2001;276: 46639-46646.

38 Thornberry NA, Lazebnik Y: Caspases: enemies within. Science 1998;281:1312-1316.

-39 Gross A, Yin XM, Wang K, Wei MC, Jockel J, Milliman C, Erdjument-Bromage H, Tempst P, Korsmeyer SJ: Caspase cleaved BID targets mitochondria and is required for cytochrome c release, while BCL-XL prevents this release but not tumor necrosis factor-R1/Fas death. J Biol Chem 1999;274: $1156-1163$.

40 Cilenti L, Soundarapandian MM, Kyriazis GA, Stratico V, Singh S, Gupta S, Bonventre JV, Alnemri ES, Zervos AS: Regulation of HAX-1 anti-apoptotic protein by $\mathrm{Omi} / \mathrm{HtrA} 2$ protease during cell death. J Biol Chem 2004;279:50295-50301.

41 Degli Esposti M: Mitochondria in apoptosis: past, present and future. Biochem Soc Trans 2004;32: 493-495.

42 Jiang X, Wang X: Cytochrome C-mediated apoptosis. Annu Rev Biochem 2004;73:87-106.

43 Kroemer G, Martin SJ: Caspase-independent cell death. Nat Med 2005;11:725-730.

44 Chang HY, Nishitoh H, Yang X, Ichijo H, Baltimore D: Activation of apoptosis signal-regulating kinase 1 (ASK1) by the adapter protein Daxx. Science 1998;281:1860-1863.

45 Kelliher MA, Grimm S, Ishida Y, Kuo F, Stanger BZ, Leder P: The death domain kinase RIP mediates the TNF-induced NF-kappaB signal. Immunity 1998;8:297-303.

46 Scaffidi C, Schmitz I, Krammer PH, Peter ME: The role of c-FLIP in modulation of CD95-induced apoptosis. J Biol Chem 1999;274:1541-1548.

47 Rochat-Steiner V, Becker K, Micheau O, Schneider P, Burns K, Tschopp J: FIST/HIPK3: a Fas/FADDinteracting serine/threonine kinase that induces FADD phosphorylation and inhibits fas-mediated Jun NH(2)-terminal kinase activation. J Exp Med 2000;192:1165-1174.

48 Chu K, Niu X, Williams LT: A Fas-associated protein factor, FAF1, potentiates Fas-mediated apoptosis. Proc Natl Acad Sci USA 1995;92:1189411898.

49 Sato T, Irie S, Kitada S, Reed JC: FAP-1: a protein tyrosine phosphatase that associates with Fas. Science 1995;268:411-415.

50 Imai Y, Kimura T, Murakami A, Yajima N, Sakamaki K, Yonehara S: The CED-4-homologous protein FLASH is involved in Fas-mediated activation of caspase-8 during apoptosis. Nature 1999; 398:777-785.

-51 Schlottmann KE, Gulbins E, Lau SM, Coggeshall KM: Activation of Src-family tyrosine kinases during Fas-induced apoptosis. J Leukoc Biol 1996;60: 546-554.

\$5 Okura T, Gong L, Kamitani T, Wada T, Okura I, Wei CF, Chang HM, Yeh ET: Protection against Fas/APO-1- and tumor necrosis factor-mediated cell death by a novel protein, sentrin. J Immunol 1996;157:4277-4281.

53 Wright DA, Futcher B, Ghosh P, Geha RS: Association of human fas (CD95) with a ubiquitin-conjugating enzyme (UBC-FAP). J Biol Chem 1996;271: 31037-31043.

54 Wallach D, Varfolomeev EE, Malinin NL, Goltsev YV, Kovalenko AV, Boldin MP: Tumor necrosis factor receptor and Fas signaling mechanisms. Annu Rev Immunol 1999;17:331-367.
5 O'Flaherty E, Wong WK, Pettit SJ, Seymour K, Ali S, Kirby JA: Regulation of T-cell apoptosis: a mixed lymphocyte reaction model. Immunology 2000;100: 289-299.

56 Refaeli Y, van Parijs L, London CA, Tschopp J, Abbas AK: Biochemical mechanisms of IL-2-regulated Fas-mediated $\mathrm{T}$ cell apoptosis. Immunity 1998;8:615-623.

57 Haux J, Johnsen AC, Steinkjer B, Egeberg K, Sundan A, Espevik T: The role of interleukin-2 in regulating the sensitivity of natural killer cells for Fasmediated apoptosis. Cancer Immunol Immunother 1999;48:139-146.

58 Li XC, Demirci G, Ferrari-Lacraz S, Groves C, Coyle A, Malek TR, Strom TB: IL-15 and IL-2: a matter of life and death for T cells in vivo. Nat Med 2001;7:114-118

59 Lenardo MJ: Fas and the art of lymphocyte maintenance. J Exp Med 1996;183:721-724.

60 Nagata S: Fas ligand-induced apoptosis. Annu Rev Genet 1999;33:29-55.

61 Lim MS, Straus SE, Dale JK, Fleisher TA, StetlerStevenson M, Strober W, Sneller MC, Puck JM, Lenardo MJ, Elenitoba-Johnson KS, Lin AY, Raffeld M, Jaffe ES: Pathological findings in human autoimmune lymphoproliferative syndrome. Am J Pathol 1998;153:1541-1550.

62 Bleesing JJ, Brown MR, Novicio C, Guarraia D, Dale JK, Straus SE, Fleisher TA: A composite picture of TcR alpha/beta(+) CD4(-)CD8(-) T Cells (alpha/beta-DNTCs) in humans with autoimmune lymphoproliferative syndrome. Clin Immunol 2002; 104:21-30.

63 Rieux-Laucat F, Le Deist F, Fischer A: Autoimmune lymphoproliferative syndromes: genetic defects of apoptosis pathways. Cell Death and Differentiation 2003;10:124-133.

64 Fuss IJ, Strober W, Dale JK, Fritz S, Pearlstein GR, Puck JM, Lenardo MJ, Straus SE: Characteristic T helper $2 \mathrm{~T}$ cell cytokine abnormalities in autoimmune lymphoproliferative syndrome, a syndrome marked by defective apoptosis and humoral autoimmunity. J Immunol 1997;158:1912-1918.

65 Zhang ZX, Yang L, Young KJ, DuTemple B, Zhang L: Identification of a previously unknown antigenspecific regulatory $\mathrm{T}$ cell and its mechanism of suppression. Nat Med 2000;6:782-789.

66 Watanabe D, Suda T, Hashimoto H, Nagata S: Constitutive activation of the Fas ligand gene in mouse lymphoproliferative disorders. EMBO J 1995;14: 12-18.

-67 De la Calle-Martin O, Hernandez M, Ordi J, Casamitjana N, Arostegui JI, Caragol I, Ferrando M, Labrador M, Rodriguez-Sanchez JL, Espanol T: Familial CD8 deficiency due to a mutation in the CD8 alpha gene. J Clin Invest 2001;108:117-123.

68 Bleesing JJ, Brown MR, Straus SE, Dale JK, Siegel RM, Johnson M, Lenardo MJ, Puck JM, Fleisher TA: Immunophenotypic profiles in families with autoimmune lymphoproliferative syndrome. Blood 2001;98:2466-2473.

69 Poppema S, Maggio E, van den Berg A: Development of lymphoma in autoimmune lymphoproliferative syndrome (ALPS) and its relationship to Fas gene mutations. Leuk Lymphoma 2004;45:423-431.

70 Barry M, Bleackley RC: Cytotoxic T lymphocytes: all roads lead to death. Nat Rev Immunol 2002;2: 401-409.

71 Grimaldi CM, Hicks R, Diamond B: B cell selection and susceptibility to autoimmunity. J Immunol 2005;174:1775-1781.
2 Wang J, Lobito AA, Shen F, Hornung F, Winoto A, Lenardo MJ: Inhibition of Fas-mediated apoptosis by the B cell antigen receptor through c-FLIP. Eur J Immunol 2000;30:155-163.

73 Deutsch M, Tsopanou E, Dourakis SP: The autoimmune lymphoproliferative syndrome (CanaleSmith) in adulthood. Clin Rheumatol 2004;23:4344.

74 Dianzani U, Chiocchetti A, Ramenghi U: Role of inherited defects decreasing Fas function in autoimmunity. Life Sci 2003;72:2803-2824.

75 Straus SE, Jaffe ES, Puck JM, Dale JK, Elkon KB, Rosen-Wolff A, Peters AM, Sneller MC, Hallahan CW, Wang J, Fischer RE, Jackson CM, Lin AY, Baumler C, Siegert E, Marx A, Vaishnaw AK, Grodzicky T, Fleisher TA, Lenardo MJ: The development of lymphomas in families with autoimmune lymphoproliferative syndrome with germline Fas mutations and defective lymphocyte apoptosis. Blood 2001;98:194-200

76 Clementi R, Dagna L, Dianzani U, Dupre L, Dianzani I, Ponzoni M, Cometa A, Chiocchetti A, Sabbadini MG, Rugarli C, Ciceri F, Maccario R, Locatelli F, Danesino C, Ferrarini M, Bregni M: Inherited perforin and Fas mutations in a patient with autoimmune lymphoproliferative syndrome and lymphoma. N Engl J Med 2004;351:1419-1424.

77 Catalfamo M, Henkart PA: Perforin and the granule exocytosis cytotoxicity pathway. Curr Opin Immunol 2003;15:522-527.

78 Andrews BS, Eisenberg RA, Theofilopoulos AN, Izui S, Wilson CB, McConahey PJ, Murphy ED, Roths JB, Dixon FJ: Spontaneous murine lupuslike syndromes. Clinical and immunopathological manifestations in several strains. J Exp Med 1978; 148:1198-1215.

79 Watanabe T, Sakai Y, Miyawaki S, Shimizu A, Koiwai $\mathrm{O}$, Ohno K: A molecular genetic linkage map of mouse chromosome 19, including the lpr, Ly-44, and Tdt genes. Biochem Genet 1991;29:325-335.

80 Roths JB, Murphy ED, Eicher EM: A new mutation, gld, that produces lymphoproliferation and autoimmunity in $\mathrm{C} 3 \mathrm{H} / \mathrm{HeJ}$ mice. J Exp Med 1984; 159:1-20.

81 Watson ML, D'Eustachio P, Mock BA, Steinberg AD, Morse HC 3rd, Oakey RJ, Howard TA, Rochelle JM, Seldin MF: A linkage map of mouse chromosome 1 using an interspecific cross segregating for the gld autoimmunity mutation. Mamm Genome 1992;2:158-171.

82 Matsuzawa A, Moriyama T, Kaneko T, Tanaka M, Kimura M, Ikeda H, Katagiri T: A new allele of the Ipr locus, lpreg, that complements the gld gene in induction of lymphadenopathy in the mouse. J Exp Med 1990;171:519-531.

83 Cohen PL, Eisenberg RA: Lpr and gld: single gene models of systemic autoimmunity and lymphoproliferative disease. Annu Rev Immunol 1991;9: 243-269.

84 Adachi M, Watanabe-Fukunaga R, Nagata S: Aberrant transcription caused by the insertion of an early transposable element in an intron of the Fas antigen gene of lpr mice. Proc Natl Acad Sci US A 1993;90:1756-1760.

85 Krammer PH, Dhein J, Walczak H, Behrmann I, Mariani S, Matiba B, Fath M, Daniel PT, Knipping E, Westendorp MO, Stricker K, Baumler C, Hellbardt S, Germer M, Peter ME, Debatin KM: The role of APO-1-mediated apoptosis in the immune system. Immunol Rev 1994;142:175-191. 
86 Kobayashi S, Hirano T, Kakinuma M, Uede T: Transcriptional repression and differential splicing of Fas mRNA by early transposon (ETn) insertion in autoimmune lpr mice. Biochem Biophys Res Commun 1993;191:617-624.

87 Kasahara Y, Wada T, Niida Y, Yachie A, Seki H, Ishida Y, Sakai T, Koizumi F, Koizumi S, Miyawaki T, Taniguchi N: Novel Fas (CD95/APO-1) mutations in infants with a lymphoproliferative disorder. Int Immunol 1998;10:195-202.

88 Wu J, Wilson J, He J, Xiang L, Schur PH, Mountz JD: Fas ligand mutation in a patient with systemic lupus erythematosus and lymphoproliferative disease. J Clin Invest 1996;98:1107-1113.

89 Wang J, Zheng L, Lobito A, Chan FK, Dale J, Sneller M, Yao X, Puck JM, Straus SE, Lenardo MJ: Inherited human caspase 10 mutations underlie defective lymphocyte and dendritic cell apoptosis in autoimmune lymphoproliferative syndrome type II. Cell 1999;98:47-58.

90 Van der Burg M, de Groot R, Comans-Bitter WM, den Hollander JC, Hooijkaas H, Neijens HJ, Berger RM, Oranje AP, Langerak AW, van Dongen JJ: Autoimmune lymphoproliferative syndrome (ALPS) in a child from consanguineous parents: a dominant or recessive disease? Pediatr Res 2000; 47:336-343.

91 Itoh N, Nagata S: A novel protein domain required for apoptosis. Mutational analysis of human Fas antigen. J Biol Chem 1993;268:10932-10937.

92 Bona G, Defranco S, Chiocchetti A, Indelicato M, Biava A, Difranco D, Dianzani I, Ramenghi U, Corrias A, Weber G, De Sanctis V, Iughetti L, Radetti G, Dianzani U: Defective function of Fas in $\mathrm{T}$ cells from paediatric patients with autoimmune thyroid diseases. Clin Exp Immunol 2003; 133:430-437.

93 Jackson CE, Puck JM: Autoimmune lymphoproliferative syndrome, a disorder of apoptosis. Curr Opin Pediatr 1999;11:521-527.

94 Chun HJ, Zheng L, Ahmad M, Wang J, Speirs CK, Siegel RM, Dale JK, Puck J, Davis J, Hall CG, Skoda-Smith S, Atkinson TP, Straus SE, Lenardo MJ: Pleiotropic defects in lymphocyte activation caused by caspase- 8 mutations lead to human immunodeficiency. Nature 2002;419:395-399.

95 Grzela T, Krauze A, Grzela K, Lazarczyk M, Niderla J, Brawura-Biskupski-Samaha R, Dziunycz P, Milewski L, Korczak-Kowalska G, Kulus M: Impaired apoptosis of lymphocytes derived from patient with decreased expression of caspase- 8 results in Alps-like phenotype. Int J Mol Med 2004;14: 937-942.

96 Wang J, Lenardo MJ: Roles of caspases in apoptosis, development, and cytokine maturation revealed by homozygous gene deficiencies. J Cell Sci 2000; 113:753-757.

-97 Wang EC, Thern A, Denzel A, Kitson J, Farrow SN, Owen MJ: DR3 regulates negative selection during thymocyte development. Mol Cell Biol 2001;21: 3451-61.

-98 Liu J, Na S, Glasebrook A, Fox N, Solenberg PJ, Zhang Q, Song HY, Yang DD: Enhanced CD4+ $\mathrm{T}$ cell proliferation and $\mathrm{Th} 2$ cytokine production in DR6-deficient mice. Immunity 2001;15:23-34.

-99 Ramenghi U, Bonissoni S, Migliaretti G, DeFranco S, Bottarel F, Gambaruto C, DiFranco D, Priori R, Conti F, Dianzani I, Valesini G, Merletti F, Dianzani U: Deficiency of the Fas apoptosis pathway without Fas gene mutations is a familial trait predisposing to development of autoimmune diseases and cancer. Blood 2000;95:3176-3182. 